\title{
Nursing Home and Hospice
}

\section{Hospitalization of Nursing Home Residents: The Effects of States' Medicaid Payment and Bed-Hold Policies}

\author{
Orna Intrator, David C. Grabowski, Jacqueline Zinn, Mark \\ Schleinitz, Zhanlian Feng, Susan Miller, and Vince Mor
}

Objective. Hospitalizations of nursing home residents are costly and expose residents to iatrogenic disease and social and psychological harm. Economic constraints imposed by payers of care, predominantly Medicaid policies, are hypothesized to impact hospitalizations.

Data Sources/Study Setting. Federally mandated resident assessments were merged with Medicare claims and eligibility files to determine hospitalizations and death within 150 days of baseline assessment. Nursing home and market characteristics were obtained from the Online Survey Certification and Reporting, and the Area Resource File, respectively. States' average daily Medicaid nursing home payments and bed-hold policies were obtained independently.

Study Design. Prospective cohort study of 570,614 older ( $\geq 65$-year-old), non-MCO (Medicare Managed Care), long-stay ( $\geq 90$ days) residents in 8,997 urban, freestanding nursing homes assessed between April and June 2000, using multilevel models to test the impact of state policies on hospitalizations controlling for resident, nursing home, and market characteristics.

Principal Findings. Overall, 99,379 (17.4 percent) residents were hospitalized with rates varying from 8.4 percent in Utah to 24.9 percent in Louisiana. Higher Medicaid per diem was associated with lower odds of hospitalizations (5 percent lower for each $\$ 10$ above average $\$ 103.5$, confidence intervals [CI] 0.91-0.99). Hospitalization odds were higher by 36 percent in states with bed-hold policies (CI: 1.12-1.63).

Conclusions. State Medicaid bed-hold policy and per-diem payment have important implications for nursing home hospitalizations, which are predominantly financed by Medicare. This study emphasizes the importance of properly aligning state Medicaid and federal Medicare policies in regards to the subsidy of acute, maintenance, and preventive care in the nursing home setting.

Key Words. Multilevel models, Medicare, long-term-care, pay for performance 
Hospitalization of nursing home residents is prevalent throughout the U.S., but varies considerably both within and between states (Intrator and Mor 2004; Intrator, Zinn, and Mor 2004). Over 15 percent of long-stay nursing home residents are hospitalized within a given 6 -month period (Intrator, Zinn, and Mor 2004). Hospitalizations are costly and put residents at risk for iatrogenic disease and delirium (Ouslander, Weinberg, and Phillips 2000). In addition to resident characteristics and severity of illness, facility, and market characteristics are associated with the likelihood of hospitalization of nursing home residents (Intrator, Zinn, and Mor 2004). Although hospitalization rates vary across states, even when controlling for facility and market factors, there has been little systematic study of the influence of state Medicaid nursing home policies on these rates.

Over 60 percent of nursing home resident care, and an even higher percentage of long-stay resident care, is paid for by states' Medicaid programs that differ considerably in the generosity and method of payment (Harrington et al. 1999; Grabowski et al. 2004). States have broad discretion to set the daily Medicaid nursing home payment rate (Wiener and Stevenson 1998). States' nursing home policies have been shown to be associated with quality measures (Grabowski, Angelelli, and Mor 2004; Zhang and Grabowski 2004), expenditures (Harrington and Swan 1987), and access to services (Ettner 1993).

In response to less generous Medicaid payments, nursing homes appear to reduce staffing (Cohen and Spector 1996; Grabowski 2001a, b; Grabowski, Angelelli, and Mor 2004; Intrator et al. 2005) and the use of nurse practitioners or physician assistants (NP/PAs; Intrator et al. 2005). In facilities with inadequate staffing, temporary acute conditions are more likely to occur, and less likely to be well managed, typically necessitating hospitalization (Ackermann and Kemle 1998; Intrator, Castle, and Mor 1999; Reuben et al. 1999; Intrator and Mor 2004; Intrator, Zinn, and Mor 2004). Yet, there has been insufficient research on the direct relationship between state Medicaid nursing home policies and hospitalizations. In the only published study of this issue, Intrator and Mor used 1993 data from nursing homes in 10 states and showed that a

Address correspondence to Orna Intrator, Ph.D., Brown University, Box G-ST2, Providence, RI 02912. David C. Grabowski, Ph.D., is with the Department of Health Care Policy, Harvard Medical School, Boston, MA. Jacqueline Zinn, Ph.D., is with the Fox School of Business and Management, Temple University, Philadelphia, PA. Mark Schleinitz, M.D. M.S., is with Rhode Island Hospital, Providence, RI. Zhanlian Feng, Ph.D, and Susan Miller, Ph.D., are with the Center for Gerontology and Health Care Research, Brown University, Providence, RI. Vincent Mor, Ph.D., is with the Department of Community Health, Brown University, Providence, RI. 
$\$ 10$ Medicaid payment rate higher than the average Medicaid rate across states $(\$ 100)$ was associated with a 9 percent lower odds of hospitalization (Intrator and Mor 2004).

Bed-hold policies pay nursing homes to reserve the bed of acutely hospitalized residents, and vary across states in the proportion of the average Medicaid daily rate paid for bed-hold, and the number of days covered. Some states also require a minimum facility occupancy rate to qualify for bed-hold payments. The goal of bed-hold is to provide a continuous place of residence for the nursing home resident. In the absence of a bed-hold policy, some residents may refuse hospitalization to avoid loss of their bed (Nohlgren 2004). On the other hand, if the marginal profit associated with the Medicaid bedhold payment is greater than the marginal profit associated with nursing home Medicaid payment for continued care in the nursing home, then bed-hold introduces a financial incentive to hospitalize nursing home residents. Using the Institutional Population Component of the 1987 National Medical Expenditures Survey, Freiman and Murtaugh (1993) found a positive, but statistically insignificant association between the presence of a state bed-hold policy and nursing home hospitalization.

In this paper, we used national data from 2000 to analyze the association between state Medicaid policies and the probability of acute hospitalization from the nursing home setting, using multilevel multinomial response models controlling for death and for resident, facility, and market factors that may influence hospitalization.

\section{METHODS}

\section{Data Sources}

We merged data from mandated assessments of nursing home residents, Medicare claims and eligibility files, annual nursing home certification surveys, county-level market measures, and state-level policies collected via our own survey. All data pertain to the study year, 2000.

The minimum data set (MDS) resident assessment instrument, in use in nursing homes since 1991, has nearly 400 data items, including cognitive functioning, physical functioning, diagnoses, health conditions, and more, which provide information on resident case-mix acuity. The Centers for Medicare and Medicaid Services (CMS) mandates that all residents treated in a federally certified nursing home for at least 14 days be assessed quarterly, at admission, readmission, discharge, and when a significant change in health 
status occurs (Morris et al. 1990, 1997). We used MDS data from CMS's MDS Repository from all 48 contiguous U.S. states (excluding Hawaii, Alaska, and the District of Columbia because they are either remote or have political constraints beyond those of the other states). MDS data were merged with Medicare eligibility files for the same time period to determine cohort eligibility, and with inpatient claims to determine inpatient hospital utilization.

Facility characteristics were obtained from the On-line Survey of Certification and Reporting (OSCAR) annual report closest to July 1, 2000. OSCAR provides information on nursing home structure (proprietary status, number of beds, hospital affiliation, etc.), staffing, resident case mix, and service availability. The many studies that have used the OSCAR data provide evidence of its validity (Weech-Maldonado, Neff, and Mor 2003; Zinn et al. 2003; Feng et al. 2005; Intrator et al. 2005).

Nursing home markets are frequently defined as counties because of patterns of funding and patient origin (Joskow 1980; Nyman 1985; Zinn 1994; Banaszak Holl, Zinn, and Mor 1996). Although this may be a suboptimal approximation (Zwanziger, Mukamel, and Indridason 2002), aggregate data based on other geographic market definitions are not readily available. We used the Area Resource File, a county-level database containing socioeconomic data, as well as availability of medical professionals and services, to control for market heterogeneity in supply and demand for nursing home services (Stambler 1988).

We collected data on state policies via a comprehensive survey of state nursing home policies and used states' average daily Medicaid nursing home payment and bed-hold policies from 2000 (Grabowski et al. 2004).

\section{Cohort Definition}

Given differences in urban and rural nursing home markets, we excluded rural nursing homes because they are more isolated, and their hospitalization patterns, including the response to state policies, may be influenced by external resource constraints, such as travel distance, beyond those found in urban settings (Zwanziger, Mukamel, and Indridason 2002). We also excluded 145 (1.5 percent) nursing homes with fewer than 20 beds because we believe their incentives for operation would be very different than those of larger facilities, and, based on information in the OSCAR, we observed that they cater to very select populations. 
We limited our analysis to long-stay nursing home residents. Residents recently admitted for short-stay rehabilitation and skilled nursing following a hospitalization may be more likely to be readmitted to the hospital due to medical instability associated with their initial hospitalization (Gillen et al. 1996; Intrator, Castle, and Mor 1999; Intrator, Zinn, and Mor 2004). Moreover, it is likely that nursing home staff are more familiar with long-stay residents' conditions, and have had more opportunity to provide them with better maintenance and preventive services (Saliba et al. 2000). Residents in hospitalbased facilities were not included in this study because these facilities primarily provide services to residents receiving postacute care or awaiting placement in community nursing homes. Hospital-based nursing homes also have resource sharing arrangements with their affiliated hospitals that potentially influence their utilization standards, such that the impact of Medicaid policies may be different on these nursing homes than on freestanding nursing homes.

Conceptually, long stayers are $\mathrm{NH}$ residents who are in the $\mathrm{NH}$ for continued or custodial care. Residents may initially be admitted for postacute care, and then change their intention and become custodial or long-term care. Therefore, the definition of a long-stay resident changes over time. As no clear indication for reason of stay exists in the MDS assessments, we approximate it by using uninterrupted length of stay. All admission, quarterly, annual, substantial change, and other Medicare-required MDS assessments from the second quarter of 2000 were eligible as baseline cohort admitting assessments. Residents who remained in the nursing home throughout the quarter generally have a quarterly, or annual, MDS assessment around 90 days before the baseline assessment, thus we allowed the prior assessment to be within 120 days. However, an assessment that was completed earlier than 90 days raised concerns that the residents' tenure in the nursing home was $<90$ days. In these cases, long-stay status was attained only if there was an additional prior assessment within 210 days, a reasonable time period for another required MDS assessment. Thus, generally, a minimum of two prior assessments were required to identify a continuous residence in a nursing home of at least 90 days.

The cohort included noncomatose residents 65 years old or older. We excluded residents in swing-bed facilities, and those not matched to Medicare enrollment records. We also excluded residents who were enrolled in a health maintenance organization (HMO) at any time during calendar year 2000 as complete utilization data were lacking for these individuals. Of the 1,740,074 individuals in a nursing home in the 48 states at some point in the second quarter of 2000 , roughly one-third of the residents $(572,557)$ were eligible for 
inclusion in this study. Although not mutually exclusive, the majority of residents excluded resided in rural nursing homes (22.4 percent), were short-stay residents (15.5 percent), had no Medicare match (11.7 percent), or were HMO enrollees (6.1 percent).

Missing resident data were imputed from the closest prior MDS assessment. Imputation was most common for items only available on the annual assessment such as DNR orders (imputed for 15 percent of residents), and race (imputed for 2 percent of residents). In total, $<0.5$ percent of residents were dropped due to other missing data. The final analytic sample included 570,614 residents in 8,997 nursing homes in 812 counties in the 48 contiguous U.S. states.

\section{Outcome}

We used Medicare claims assembled in CMS' inpatient standard analytic file (SAF) to determine all hospitalizations of cohort residents within 150 days of the resident's baseline assessment date. We used CMS' denominator file to determine dates of death. Following previously published studies we defined a categorical outcome by first identifying those residents who were hospitalized, then, among those residents who were not hospitalized, separating those individuals who died from those who survived (Mor et al. 1997; Intrator, Castle, and Mor 1999; Intrator and Mor 2004; Intrator, Zinn, and Mor 2004). This control was necessary because residents who died were presumably sicker than those who remained alive in the nursing home.

\section{State Medicaid Policy}

We used states' average Medicaid payment rates centered at the overall mean rate among the 48 states (set at $\$ 103$ ), with $\$ 10$ increments (half standard deviation). To control for geographic variation in the buying power of the dollar, we included the medical wage index in the county as a standardized covariate (Intrator and Mor 2004; CMS 2005b; Intrator et al. 2005). We included a dichotomous variable indicating states with any bed-hold policy. Of note, a $t$-test comparing the average Medicaid rates in states with or without a bed-hold policy revealed no statistically significant differences.

\section{Control Variables}

We controlled for a number of resident, facility, and market variables, many of which had been used in other studies of nursing home hospitalizations (Freiman and Murtaugh 1993; Murtaugh and Freiman 1995; Castle and Mor 1996; 
Mor et al. 1997; Intrator, Castle, and Mor 1999; Carter and Porell 2003; Intrator and Mor 2004; Intrator, Zinn, and Mor 2004; Porell and Carter 2005). At the resident-level, dummy variables were included for sociodemographic information (gender, age, race, education), several chronic diagnoses (diabetes, cancer, emphysema or chronic obstructive pulmonary disease, cancer) from among diagnoses used before (Castle and Mor 1996); and other conditions including fever, weight loss, having an unstable medical condition, impaired cognition (Cognitive Performance scale >3) (Morris et al. 1994), obesity (body mass index $>30$ ), frailty (body mass index $<19$ ), and the need for assistance in the five activities of daily living (bathing, dressing, eating, toileting, and walking). We used the Changes in Health, End-Stage Disease and Symptoms and Signs (CHESS) scale, which predicts adverse outcomes, including mortality among nursing home residents, as a summary case-mix control (Hirdes, Frijters, and Teare 2003). The model included the total number of medications, and an indicator of whether the resident was receiving any antipsychotic or hypnotic medications. Residents' preferences for care were included using an indicator whether the resident had a do-not-resuscitate (DNR) order. The model also controlled for the use of physical restraints and whether the individual received any hospice before hospitalization (because hospice patients are not expected to have acute hospitalizations). We did not consider prior hospitalizations because these could be attributable to organizational practices, and, as such, might be endogenous.

Nursing home level controls included size (number of beds), average resident acuity based on nursing minutes associated with the Resource Utilization Groups (RUGS) (Fries et al. 1994), structure (proprietary status, chain affiliation, special care units), and resident composition (percent residents on Medicaid, Medicare, and other payers). We used occupancy rates ( $>95$ percent) as a proxy for financial stability (Weech-Maldonado, Neff, and Mor 2003). In terms of staffing, we included the ratio of registered nurses to total nurses (Porell and Carter 2005), indicators for nurse staffing above the recommended 4.55 hours per resident day (Harrington et al. 2000), nursing home employment of any NP/PA (Intrator, Castle, and Mor 1999; Intrator, Zinn, and Mor 2004; Intrator et al. 2005), and nursing home employment of at least one half full-time equivalent physician who was not the medical director (Intrator, Zinn, and Mor 2004).

At the market level, we controlled for nursing home competition using a Herfindahl index, a measure of industry concentration equal to the sum of the squared market shares (beds) of all facilities in the market (county) (Zinn 1994). Lower values of the Herfindahl index generally indicate a loss of pricing 
power and greater competition, whereas higher values imply the opposite. The U.S. Department of Justice considers a market with a Herfindahl index between 0.10 and 0.18 to be moderately concentrated (and hence moderately competitive) and a market with an Herfindahl index below 0.10 to be less concentrated, or highly competitive (http://www.usdoj.gov/atr/public/ testimony/hhi.htm). Thus, we employ a dummy variable indicating whether the market was highly competitive (Herfindahl index $<0.10)$. We also controlled for market income (as measured by per capita income), demand for services (percent population aged $75+$ ), and availability of resources (number of hospital beds per 1,000 population $75+$ years old).

Continuous variables were scaled by standardizing (to reflect the number of standard deviations from their sample mean) in order to allow easier comparison of the effects across variables, and to prevent overestimation. Centering of variables was important in order to avoid misleading variance component estimates in these multilevel models (Goldstein, Rasbash, and Plewis 1998). Importantly, the results presented in this paper are robust to treating all variables in the model as continuous measures.

\section{Statistical Analyses}

We use $M L W i N($ Goldstein, Rasbash, and Plewis 1998) to specify a multilevel model in which residents were nested within nursing homes that were nested within markets that were nested in states (Goldstein 1995; Bravo et al. 1999; Snijders and Bosker 1999; Intrator, Zinn, and Mor 2004). Multilevel models postulate that residents in the same facility share unmeasured characteristics which contribute to their unique variation in terms of hospitalizations, as do facilities in the same market, and markets in the same state. By specifying the correct partitioning of the variance, multilevel models estimates of effect sizes and their standard errors, as well as variance components, are consistent. Within the multilevel framework, the three-category multinomial response model was estimated by two binary response models, one contrasting hospitalizations to the referent category of remained alive, and the other contrasting deaths without having been hospitalized to the referent category. This estimation method was necessary in order to handle the large data file, although it produces results with somewhat less efficient estimates than those obtained by estimation of the full multinomial response model (Begg and Gray 1984). A sensitivity analysis estimating the full multinomial response multilevel model on a random 10 percent sample produced similar estimates, confirming our estimation approach. Results from unbiased Markov Chain 
Monte Carlo (MCMC) estimates are presented (Goldstein, Browne, and Rasbash 2002). For ease of interpretation, multivariate results are presented as effects on the adjusted odds ratios (AOR) with 95 percent confidence intervals (CI).

\section{RESULTS}

\section{Descriptive Statistics}

Among the 570,614 cohort residents, 99,379 (17.4 percent) were hospitalized within 150 days, and 54,724 (9.6 percent) died without being hospitalized (see Table 1). Another 34,163 residents (6 percent) died at some point over the 5 months posthospitalization, resulting in 88,887 long-stay resident deaths within 5 months. Most of the hospitalized residents were hospitalized once (76.5 percent), but 17.4 percent had two hospitalizations, and 6.1 percent had three or more hospitalizations during the observation period. Hospitalization rates varied across states from 8.4 percent in Utah to 24.9 percent in Louisiana (see Figure 1).

Figure 1: Five Months Hospitalization Rates of Long-Stay Nursing Home Residents by State in 2000

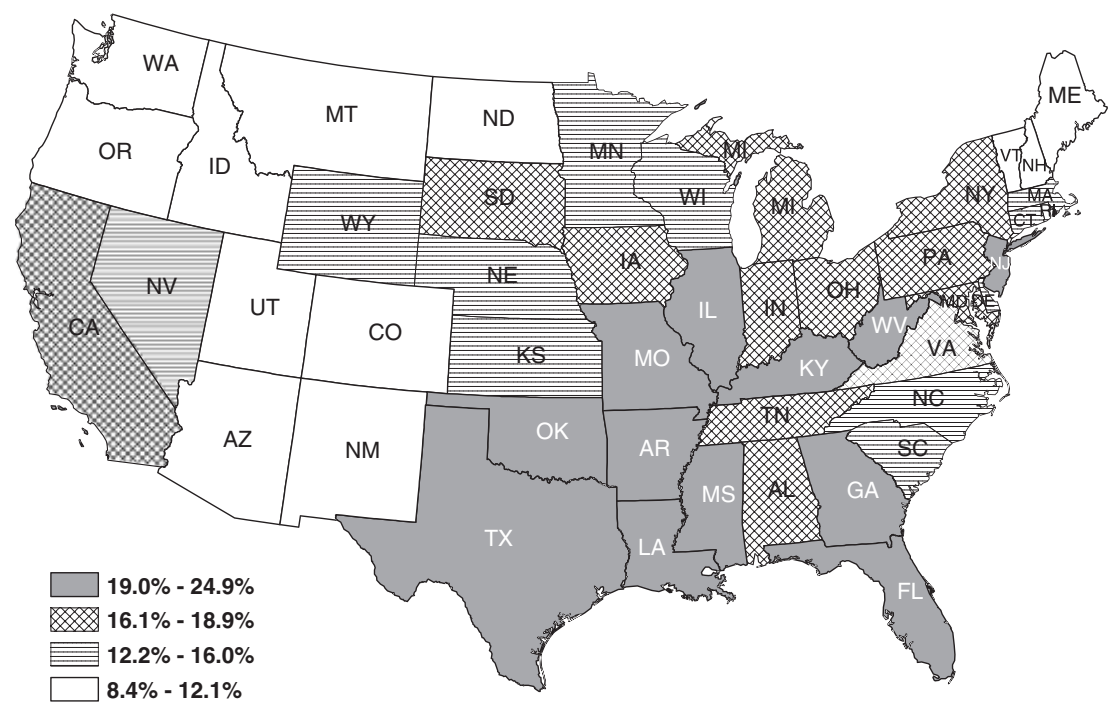


Table 1: Characteristics of Long-Stay Residents in Urban Freestanding Nursing Homes $(N=570,614)$

\begin{tabular}{|c|c|c|}
\hline Resident Variables & $N$ & $\%$ \\
\hline \multicolumn{3}{|l|}{ Dependent variable } \\
\hline Hospitalized & 99,379 & 17.4 \\
\hline Not hospitalized but died & 54,724 & 9.6 \\
\hline Neither hospitalized nor died & 416,511 & 73.0 \\
\hline \multicolumn{3}{|l|}{ Demographics } \\
\hline Male & 129,886 & 22.8 \\
\hline \multicolumn{3}{|l|}{ Race/ethnicity } \\
\hline White & 487,018 & 85.4 \\
\hline African American & 60,270 & 10.6 \\
\hline Other & 22,326 & 4.0 \\
\hline \multicolumn{3}{|l|}{ Age } \\
\hline$<75$ & 73,442 & 12.9 \\
\hline $75-85$ & 205,296 & 36.0 \\
\hline $85-95$ & 241,922 & 42.4 \\
\hline$>95$ & 49,954 & 8.7 \\
\hline \multicolumn{3}{|l|}{ Education } \\
\hline College & 75,043 & 13.1 \\
\hline More than high school & 98,862 & 17.1 \\
\hline High school & 175,147 & 30.7 \\
\hline Unknown & 74,472 & 13.1 \\
\hline \multicolumn{3}{|l|}{ Diagnoses } \\
\hline Diabetes & 123,677 & 21.7 \\
\hline $\mathrm{CHF}$ & 90,436 & 15.9 \\
\hline Emphysema/COPD & 59,033 & 10.4 \\
\hline Cancer & 29,060 & 5.1 \\
\hline \multicolumn{3}{|l|}{ Condition } \\
\hline Unstable condition & 177,213 & 31.1 \\
\hline Fever & 6,963 & 1.2 \\
\hline \multicolumn{3}{|l|}{ CHESS comorbidity score } \\
\hline Mild (0) & 360,345 & 63.1 \\
\hline Moderate (1-3) & 201,789 & 35.4 \\
\hline Severe $(4-5)$ & 8,480 & 1.5 \\
\hline Weight loss & 58,084 & 10.2 \\
\hline Impaired cognition & 195,754 & 34.3 \\
\hline Obese & 76,346 & 13.4 \\
\hline Low weight & 57,685 & 10.1 \\
\hline ADL completely impaired & 115,059 & 20.2 \\
\hline \multicolumn{3}{|l|}{ Treatment/preferences } \\
\hline$>9$ Medications & 173,315 & 30.4 \\
\hline Receiving antipsychotic or hypnotics & 3,110 & 0.6 \\
\hline Do-not-resuscitate order in chart & 319,418 & 56.0 \\
\hline Physical restraints & 64,146 & 11.1 \\
\hline Any hospice before hospitalization & 17,983 & 3.2 \\
\hline
\end{tabular}


Table 2: Urban Freestanding Nursing Homes: Facility, Market, and State Characteristics

\begin{tabular}{|c|c|c|c|c|}
\hline & $N$ & $\%$ & Mean & $S D$ \\
\hline \multicolumn{5}{|l|}{ State variables $(N=48)$} \\
\hline Medicaid payment rate & & & 103.50 & 19.52 \\
\hline Any bed-hold policy & 36 & 75.0 & & \\
\hline \multicolumn{5}{|l|}{ Market variables $(N=812)$} \\
\hline Herfindahl index & & & 0.26 & 0.25 \\
\hline Competitive market $($ Herfindahl $<.1$ ) & 236 & 29.1 & & \\
\hline Wage index & & & 0.96 & 0.12 \\
\hline Percent population 75 or older & & & 5.75 & 1.81 \\
\hline Population $75+$ to hospital bed & & & 48.23 & 43.32 \\
\hline Per capita income & & & $26,802.50$ & $7,683.10$ \\
\hline \multicolumn{5}{|l|}{ Facility variables $(N=8,997)$} \\
\hline Number of beds & & & 122.40 & 68.80 \\
\hline Nurse hour/resident day & & & 4.26 & 10.40 \\
\hline Nurse hour/resident day $>4.55$ & 709 & 7.9 & & \\
\hline Case-mix index & & & 0.72 & 0.06 \\
\hline Ratio RNs to total nurses & & & 0.34 & 0.20 \\
\hline Any NP/PAs & 2,001 & 22.2 & & \\
\hline$>1 / 2$ FTE physician (not Medical Director) & 377 & 4.2 & & \\
\hline Any special care unit & 1,979 & 22.0 & & \\
\hline Ratio CNAs to nurses & & & 2.67 & 9.28 \\
\hline$>15 \%$ Medicare residents & 1,337 & 14.9 & & \\
\hline$>85 \%$ Medicaid residents & 1,551 & 17.2 & & \\
\hline$>35 \%$ self paying/insured residents & 2,133 & 23.7 & & \\
\hline$>95 \%$ occupied beds & 2,536 & 28.2 & & \\
\hline For profit & 6,634 & 73.7 & & \\
\hline Part of chain & 5,350 & 59.5 & & \\
\hline Profit nonchain & 2,195 & 24.4 & & \\
\hline
\end{tabular}

Of all long-stay residents, 22.8 percent were male, 10.6 percent were African American, 34.3 percent were cognitively impaired, and 20.2 percent were severely functionally impaired. The average Medicaid payment rate was $\$ 103.50$ with a high of $\$ 160.66$ in New York and a low of $\$ 66.57$ in Oklahoma in 2000 dollars (see Table 2; Grabowski et al. 2004b). Three-quarters (36) of the 48 states had a bed-hold policy. The 12 states without any bed-hold policy were Colorado, Idaho, Nevada, Michigan, New Hampshire, North Carolina, Oregon, Rhode Island, Texas, Utah, Virginia, and Washington.

Among the 8,997 nursing homes, the average number of beds was 122 (Table 2). Although, on average, nursing homes employed 4.26 nurse hours per resident day, only 7.9 percent of facilities had more than the recommended 4.55 nurse hours per resident day. On average, roughly one-third of 
nurses in a facility were registered nurses, but this ratio varied widely among sample facilities (interquartile range 19-61 percent). Roughly 4 percent of facilities had physicians other than the medical director employed or under contract for more than one-half of a full-time equivalent.

\section{Multilevel Model Results}

Higher Medicaid payment rates were associated with lower odds of hospitalization. Every $\$ 10$ increment in the daily Medicaid payment level beyond the overall average (\$103) was significantly associated with a 5 percent lower odds of hospitalizations (AOR, 0.95 ; 95 percent CI 0.91-0.99), controlling for variability in wages, and many other characteristics (see Table 3). Nursing home residents in states with a bed-hold policy had 36 percent higher odds of being hospitalized (95 percent CI 1.12-1.63). Of note, residents in facilities with occupancy rates higher than 95 percent had 7 percent lower odds of being hospitalized than residents in facilities with lower occupancy rates (CI 0.91-0.96).

The relevance of supply and demand of nursing home services in the market to hospitalizations is also of interest. Nursing home residents of facilities in more competitive markets had 8 percent higher odds of being hospitalized than residents in less competitive markets (CI 1.03-1.12). Residents in markets with a higher ratio of hospital beds to population aged 75 and older also had higher odds of being hospitalized. Neither population demographics (percent population 75 or older) nor average income in the market (per capita income) were associated with hospitalizations.

Results that pertain to the facility staffing variables corresponded with prior results (Mor et al. 1997; Intrator, Castle, and Mor 1999; Carter and Porell 2003; Intrator, Zinn, and Mor 2004). Staffing variables associated with reduced hospitalization rates included nurse staffing beyond the recommended 4.55 hours per resident day (AOR 0.94, CI 0.90-0.99), the availability of NP/ PAs (AOR 0.96, CI 0.94-0.99), and the ratio of RNs to total nurses (AOR $=0.78$, CI 0.73-0.83).

The complementary results of the mortality model (compared with survived and not hospitalized) showed a 3 percent higher odds of death for every $\$ 10$ increment in Medicaid rate, and 17 percent lower odds of death for residents in state with bed-hold policies.

\section{DISCUSSION}

The decision to hospitalize a nursing home resident reflects the complex interplay of numerous characteristics of the patient, both clinical and social, 
Table 3: Multilevel Multinomial Response Model for Any Hospitalization versus No Hospitalization but Died versus Otherwise within 150 Days of Baseline MDS Assessment in the Second Quarter of 2000, Adjusting for Resident Covariates Listed in Table 1

\begin{tabular}{|c|c|c|c|c|c|c|c|}
\hline & \multirow[b]{3}{*}{ Coding } & \multicolumn{3}{|c|}{ Any Hospitalization } & \multicolumn{3}{|c|}{ Died, Not Hospitalized } \\
\hline & & \multirow[b]{2}{*}{$A O R$} & \multicolumn{2}{|c|}{$\begin{array}{c}95 \% \\
\text { Confidence } \\
\text { Interval }\end{array}$} & \multirow[b]{2}{*}{$A O R$} & \multicolumn{2}{|c|}{$\begin{array}{c}95 \% \\
\text { Confidence } \\
\text { Interval }\end{array}$} \\
\hline & & & Lower & Upper & & Lower & Upper \\
\hline \multicolumn{8}{|l|}{ State variables } \\
\hline Medicaid payment rate & $-103 / 10$ & $0.95^{* * *}$ & 0.91 & 0.99 & $1.03^{* * *}$ & 1.01 & 1.06 \\
\hline Any bed-hold policy & & $1.36^{* *}$ & 1.12 & 1.63 & $0.83^{* * *}$ & 0.74 & 0.93 \\
\hline \multicolumn{8}{|l|}{ Market variables } \\
\hline $\begin{array}{l}\text { Competitive market } \\
(\text { Herfindahl }<0.1)\end{array}$ & & $1.08^{* *}$ & 1.03 & 1.12 & $0.96^{*}$ & 0.92 & 1.00 \\
\hline Wage index & $-1.0 / 0.1$ & $1.05^{* *}$ & 1.02 & 1.07 & $0.98^{+}$ & 0.96 & 1.01 \\
\hline Percent population 75 or older & $-5.75 \%$ & 1.00 & 0.98 & 1.01 & $1.01^{*}$ & 1.00 & 1.02 \\
\hline Population $75+$ to hospital bed & $-50.0 / 43.3$ & $1.01^{* *}$ & 1.00 & 1.01 & 1.00 & 1.00 & 1.01 \\
\hline Per capita income & $-27,000 / 10,000$ & 1.00 & 0.97 & 1.03 & $1.02^{+}$ & 0.99 & 1.05 \\
\hline \multicolumn{8}{|l|}{ Facility variables } \\
\hline Nurse hour/resident day & $>4.55 \mathrm{NHPPD}$ & $0.94^{* * *}$ & 0.90 & 0.99 & 0.98 & 0.93 & 1.03 \\
\hline Ratio RNs to total nurses & -0.34 & $0.78^{* *}$ & 0.73 & 0.83 & $1.07^{*}$ & 0.99 & 1.16 \\
\hline Any NP/PAs & & $0.96^{* *}$ & 0.94 & 0.99 & 1.02 & 0.99 & 1.05 \\
\hline $\begin{array}{l}>1 / 2 \text { FTE physician } \\
\text { (not Medical Director) }\end{array}$ & & 1.00 & 0.95 & 1.06 & 1.01 & 0.95 & 1.08 \\
\hline$>95 \%$ occupied beds & & $0.93^{* *}$ & 0.91 & 0.96 & $0.92^{* * *}$ & 0.90 & 0.95 \\
\hline$>15 \%$ Medicare residents & & $1.13^{* *}$ & 1.09 & 1.17 & $1.08^{* * *}$ & 1.04 & 1.12 \\
\hline$>85 \%$ Medicaid residents & & 1.00 & 0.97 & 1.04 & $0.89^{* * *}$ & 0.85 & 0.92 \\
\hline $\begin{array}{l}>35 \% \text { Self paying/insured } \\
\text { residents }\end{array}$ & & $0.88^{* *}$ & 0.85 & 0.90 & $1.05^{* * *}$ & 1.02 & 1.09 \\
\hline Any special care unit & & $0.96 * *$ & 0.93 & 0.98 & 0.99 & 0.96 & 1.02 \\
\hline Case-mix index & $-0.72 / 0.1$ & $1.03^{* *}$ & 1.01 & 1.04 & $0.97 *$ & 0.95 & 1.00 \\
\hline Number of beds & $-120 / 30$ & $0.99^{* * *}$ & 0.98 & 0.99 & 1.00 & 1.00 & 1.01 \\
\hline For profit & & $1.06^{* *}$ & 1.02 & 1.10 & $1.05^{*}$ & 1.01 & 1.09 \\
\hline Part of chain & & $1.13^{* * *}$ & 1.09 & 1.18 & 1.00 & 0.95 & 1.04 \\
\hline Profit nonchain & & $\S$ & & & $\S$ & & \\
\hline
\end{tabular}

Four-level analysis is of 570,614 residents who were nested in 8,997 nursing homes, within 812 county-defined markets and within the 48 contiguous U.S. states.

Significance levels:

$* *<1 \%$;

$*<5 \%$

${ }^{+}<10 \%$.

${ }^{\dagger}$ Multinomial response model controls for residents who were not hospitalized but died, and not all residents who died.

${ }^{\ddagger}$ Variables that were centered or standardized are coded as $-\mathrm{X}$ for centered at $\mathrm{X}$, and $-\mathrm{X} / \mathrm{Y}$ as centered at $\mathrm{X}$ with increments of size $\mathrm{Y}$.

${ }^{8}$ Estimates of the coefficients of the effect of the interaction are not directly translatable to odds ratio. The estimated effects on the log odds are: for hospitalization $0.127(0.024)$, and for death $-0.053(.029)$.

AOR, adjusted odds ratios, NHPPD, nurse hour per patient day. 
and of the nursing home, including economic viability and staffing resources. In turn, these factors are influenced by market and state factors that impact the explicit and implicit hospitalization decisions made by facility management. Thus, the decision to hospitalize similar nursing home residents may differ across facilities, markets, and states. Controlling for a range of resident, facility and market characteristics, residents of nursing homes in states with higher Medicaid payment were somewhat less likely to be hospitalized than were similar residents in states with lower Medicaid payment (5 percent reduced odds for every $\$ 10$ increment in rate above $\$ 103$ ranging from 30 percent less in New York to 23 percent more in Oklahoma). Nursing home residents in states with bed-hold policies had 36 percent higher odds of being hospitalized than similar residents of nursing homes in states without a bedhold policy.

Not all hospitalizations are discretionary, even after controlling for resident-level covariates (Saliba et al. 2000; Intrator, Zinn, and Mor 2004). Of all residents hospitalized, 37,023 (37.3 percent) were hospitalized at least once with an ambulatory care sensitive (ACS) primary diagnosis which, given ideal care, could either have been prevented or treated in the nursing home (Culler, Parchman, and Przybylski 1998; Parchman and Culler 1999; Intrator, Zinn, and Mor 2004; Porell and Carter 2005). The analysis presented in this paper did not differentiate between nursing home residents who had a potentially preventable ACS hospitalization at any time, from those who were hospitalized, but never with an ACS diagnosis. It is our understanding that it is unlikely that Medicaid policies can target particular hospitalizations and not others. We also examined this issue by estimating a parallel multilevel multinomial response model in which residents who were hospitalized at any time during the 150 days with ACS diagnoses were separated from those who were hospitalized with other diagnoses. Our findings confirmed that the effects of state policies and market characteristics did not differ for the separated outcomes, and did not differ from the results presented here for all hospitalizations. There are several potential explanations for this result. First, there may be a lack of precision in using ACS hospitalizations to capture those truly preventable hospitalizations. Second, bed-hold policies are blunt instruments, which do not recognize whether the hospitalization was potentially preventable. Finally, in returning to the potential issue of commonality in care and spillovers across subgroups of nursing home residents, bed-hold may have implications for all hospitalization decisions (Grabowski, Gruber, and Angelelli 2006; Konetzka et al. 2006; Troyer 2004). 
States may be able to lower hospitalizations by increasing Medicaid nursing home payments (Intrator and Mor 2004). However, this result highlights the tension between Medicaid, the dominant payer of chronic nursing home services for the elderly, and Medicare, the dominant payer of hospital services, regarding the subsidy of acute care or maintenance and preventive care provided in the nursing home setting that may reduce the need for hospitalization. Nursing homes that invest in the clinical services necessary to reduce the likelihood that their residents will be hospitalized save Medicare money, but these savings do not accrue to the nursing home or to Medicaid, which must pay for the increased cost of care in the nursing home. Thus, despite the substantial savings potential for Medicare and significant health benefits for residents due to reduced hospitalizations, state Medicaid programs have little incentive to raise rates in order to limit nursing home spending on acute care. In other words, had Medicaid been budgeted to be financially responsible for nursing home residents' acute care provision, the savings from reduced acute care could balance their higher investment in nursing home services. In fact, CMS is evaluating care provision strategies that are all inclusive, such as the Program for All-inclusive Care for the Elderly (PACE).

On average states with a bed-hold policy had higher odds of hospitalization $(\mathrm{AOR}=1.36)$ which roughly translate to an additional 75 hospitalizations every 5 months for every 1,000 long-stay residents. (Average probability of hospitalization every 5 months $=17.4$ percent multiplied by increase in odds of hospitalization $=0.36$ multiplied by average number of hospitalizations among residents with any hospitalization $=1.2$.) These hospitalizations increase costs to both Medicare, which pays the hospital costs, and Medicaid, which pays to hold the nursing home bed. Whether these costs are offset by gains in either survival or quality of life deserves particular attention. On the other hand, the association between bed-hold policy and hospitalization rate may be due to residents refusing hospitalization when the status of their nursing home bed is not secured by bed-hold policy (Nohlgren 2004). Such refusals may be associated with adverse outcomes, potentially justifying the cost of bed-hold policies.

Another potentially promising mechanism for decreasing nursing home hospitalizations might be to financially reward facilities for achieving and maintaining low hospitalization rates. Although a pay-for-performance mechanism has the potential to change the immediate incentives facing nursing homes in regards to hospitalizations, it may not address the broader conflict between federal and state long-term care policies. Two recent 
pay-for-performance efforts in the nursing home sector illustrate this ongoing tension. The Ohio Medicaid program has adopted a "Quality Add-On" nursing home payment to begin in fiscal year 2007 (Ohio Legislature). Nursing homes that meet relative standards in the areas of deficiencies, resident and family satisfaction, nurse staffing, employee retention, occupancy rates, $\mathrm{Me}-$ dicaid utilization, and case mix can qualify for an add-on payment. Notably absent from this list is hospitalizations, likely in part because Ohio Medicaid receives only a small part of the savings from decreasing hospitalizations. Alternatively, CMS has begun an evaluation of pay-for-performance among the Medicare eligible population (CMS 2005a). Unlike Ohio Medicaid payfor-performance, Medicare payments to nursing homes with lower hospitalization rates can be balanced against the savings to Medicare from reduced hospitalizations. In order for state Medicaid programs to enact pay-for-performance systems to target hospitalizations, it may be necessary to introduce an explicit system for sharing the benefits of appropriately reducing hospitalization across all parties with an interest in this outcome.

The effect of a reduced hospitalization rate on residents' quality of life, and quality adjusted life years, is unknown. However, in states with no bedhold policies long-stay residents were more likely to die in place, avoiding a hospitalization which may have adversely affected their quality of life at the end of life (Creditor 1993; Saliba et al. 2000). Any subsequent pay-for-performance initiatives considering hospitalization as a performance indicator should closely monitor mortality alongside hospitalization.

Our study was limited in several ways. First, our data are observational; experimental data do not currently exist to address these research questions. It is therefore unclear whether a change in policy will result in the effect estimated in this model. Because state policies are exogenous, we postulate that the estimated effects may be attenuated, but will not change drastically. However, the analyses are cross-sectional, and cannot unambiguously rule out bias introduced by a third unobserved factor correlated with both Medicaid and bed-hold policies and nursing home hospitalization. A longitudinal study of the effect of state policies may provide more conclusive evidence by eliminating the effect of time invariant unobserved heterogeneity. Although we have controlled for facility occupancy with annually updated OSCAR data, we could not account for the day-to-day variation in occupancy that disallows bed-hold payments in certain states. Therefore, some hospitalizations in states with minimum occupancy requirements may not have resulted in bed-hold payments and the bed-hold incentive was not applicable. Finally, our cohort includes self-pay nursing home residents for whom Medicaid payments would 
not apply. Nonetheless, the potential bias introduced by these limitations, if any, would make the null hypothesis of finding no Medicaid policy association with hospitalizations more likely.

This paper presents results of a careful analysis concluding that there is a direct relationship between state Medicaid policy and the hospitalization of nursing home residents. Others have demonstrated that states' Medicaid policies are related to nursing homes' strategic investment in medical infrastructure such as staffing, which in turn also relates to hospitalization. Thus, it appears that state policies may relate to resident outcomes both directly (through their effect on unmeasured nursing home characteristics that may affect the decision to hospitalize such as improved communication via better data) and indirectly (through their effect on measured nursing home characteristics associated with hospitalization, such as the availability of NP/PAs). Future work could build on this current study to address the relationship between state Medicaid policy and hospitalizations under a broad cost-benefit framework that may account for both direct and indirect effects of states' policies. Moreover, a cost benefit analysis may be able to also account for the possibly longer hospital length-of-stay in the absence of a bed-hold policy, when placement of residents may take longer. Ideally, this line of research will suggest further strategies to improve the co-ordination of Medicaid and Medicare, while maintaining high quality resident outcomes in general, and reduced hospitalizations in particular.

\section{ACKNOWLEDGMENTS}

This research was supported by the National Institute on Aging grants R01 AG20557 and R01 AG23622 (PI: Vincent Mor), and data were analyzed under Data Use Agreement No. 12432. Dr. Grabowski was supported in part by a NIA career development award (K01 AG024403). Mark Schleinitz was supported by a Building Interdisciplinary Research Careers in Women's Health grant K12 HD43447. We appreciate the assistance of Christian Brostrup-Jensen, Jeff Hiris, and Yuwei Cang in various programming tasks, the assistance of Nancy Grossman, who conducted the state policy survey, and of two anonymous reviewers who helped shape the paper. A version of this paper was presented at the Annual Meeting of the Gerontological Society in Washington, DC in 2004, and we would like to acknowledge the discussions of David Mehr and Josh Weiner at that session.

Disclosures: None.

Disclaimers: None. 


\section{REFERENCES}

Ackermann, R. J., and K. A. Kemle. 1998. "The Effect of a Physician Assistant on the Hospitalization of Nursing Home Residents." Journal of the American Geriatrics Society 46 (5): 610-4.

Banaszak Holl, J., J. S. Zinn, and V. Mor. 1996. "The Impact of Market and Organizational Characteristics on Nursing Care Facility Service Innovation: A Resource Dependency Perspective." Health Services Research 31 (1): 97-117.

Begg, C. B., and R. Gray. 1984. "Calculation of Polychotomous Logistic Regression Parameters Using Individualized Regressions." Biometrika 71: 11-8.

Bravo, G., P. De Wals, M. F. Dubois, and M. Charpentier. 1999. "Correlates of Care Quality in Long-Term Care Facilities: A Multilevel Analysis." Journals of Gerontology Series B-Psychological Sciences and Social Sciences 54 (3): P180-8.

Carter, M. W., and F. W. Porell. 2003. "Variations in Hospitalization Rates among Nursing Home Residents: The Role of Facility and Market Attributes." Gerontologist 43 (2): 175-91.

Castle, N. G., and V. Mor. 1996. "Hospitalization of Nursing Home Residents: A Review of the Literature, 1980-1995." Medical Care Research and Review 53 (2): 123-48.

CMS. 2005a. "Nursing Home Pay for Performance Demonstration" [accessed November 3, 2006]. Available at http://www.cms.hhs.gov/apps/media/press/ release.asp?Counter $=1343$

CMS. 2005b. "Wage Index" [accessed November 3, 2006]. Available at http:// www.cms.hhs.gov/AcuteInpatientPPS/HIF/list.asp\#TopOfPage

Cohen, J., and W. Spector. 1996. "The Effect of Medicaid Reimbursement on Quality of Care in Nursing Homes." Journal of Health Economics 15 (1): 23-48.

Creditor, M. C. 1993. "Hazards of Hospitalization of the Elderly." Annals of Internal Medicine 118 (3): 219-23.

Culler, S. D., M. L. Parchman, and M. Przybylski. 1998. "Factors Related to Potentially Preventable Hospitalizations among the Elderly." Medical Care 36 (6): 804-17.

Ettner, S. L. 1993. "Do Elderly Medicaid Patients Experience Reduced Access to Nursing Home Care?" Journal of Health Economics 12 (3): 259-80.

Feng, Z., P. R. Katz, O. Intrator, J. Karuza, and V. Mor. 2005. "Physician and Nurse Staffing in Nursing Homes: The Role and Limitations of the Online Survey Certification and Reporting (OSCAR) System." Journal of the American Medical Directors Association 6 (1): 27-33.

Freiman, M. P., and C. M. Murtaugh. 1993. "The Determinants of the Hospitalization of Nursing Home Residents." Journal of Health Economics 11: 349-59.

Fries, B. E., D. P. Schneider, W. J. Foley, M. Gavazzi, R. Burke, and E. Cornelius. 1994. "Refining a Case-Mix Measure for Nursing Homes: Resource Utilization Groups (RUG-III)." Medical Care 32 (7): 668-85.

Gillen, P., D. Spore, V. Mor, and W. Freiberger. 1996. "Functional and Residential Status Transitions among Nursing Home Residents." Journals of Gerontology Series A-Biological Sciences and Medical Sciences 51 (1): M29-36. 
Goldstein, H. 1995. Multilevel Statistical Models (Kendall's Library of Statistics, Vol 3). London: Edward Arnold.

Goldstein, H., W. Browne, and J. Rasbash. 2002. "Multilevel Modelling of Medical Data." Statistics in Medicine 21 (21): 3291-315.

Goldstein, H., J. Rasbash, and I. Plewis. 1998. "A Users' Guide to MlwiN, version 2.0." Multilevel Models Project. Institute of Education. University of London.

Grabowski, D. C. 2001a. "Does an Increase in the Medicaid Reimbursement Rate Improve Nursing Home Quality?” Journals of Gerontology Series B-Psychological Sciences and Social Sciences 56 (2): S84-93.

- 2001b. "Medicaid Reimbursement and the Quality of Nursing Home Care." Journal of Health Economics 20 (4): 549-69.

Grabowski, D. C., J. J. Angelelli, and V. Mor. 2004. "Medicaid Payment and RiskAdjusted Nursing Home Quality Measures." Health Affairs (Millwood) 23 (5): 243-52.

Grabowski, D. C., J. Gruber, and J. Angelelli. 2006. "Nursing Home Quality as a Public Good." Cambridge, MA: National Bureau of Economic Research, Inc. NBER Working Paper \#12361.

Grabowski, D. C., Z. Feng, O. Intrator, and V. Mor. 2004. "Recent Trends in State Nursing Home Payment Policies." Health Affairs (Suppl Web Exclusives) W4: 363-73.

Harrington, C., C. Kovner, M. Mezey, J. Kayser-Jones, S. Burger, M. Mohler, R. Burke, and D. Zimmerman. 2000. "Experts Recommend Minimum Nurse Staffing Standards for Nursing Facilities in the United States." Gerontologist 40 (1): 5-16.

Harrington, C., and J. H. Swan. 1987. "The Impact of State Medicaid Nursing Home Policies on Utilization and Expenditures." Inquiry 24 (2): 157-72.

Harrington, C., J. H. Swan, V. Wellin, W. Clemena, B. Bedney, and H. Carillo. 1999. 1998 State Data Book on Long Term Care Program and Market Characteristics. San Francisco: University of California, Department of Social and Behavioral Sciences.

Hirdes, J. P., D. H. Frijters, and G. F. Teare. 2003. "The MDS-CHESS Scale: A New Measure to Predict Mortality in Institutionalized Older People." Journal of the American Geriatrics Society 51 (1): 96-100.

Intrator, O., N. G. Castle, and V. Mor. 1999. "Facility Characteristics Associated with Hospitalization of Nursing Home Residents: Results of a National Study." Medical Care 37 (3): 228-37.

Intrator, O., Z. Feng, V. Mor, D. Gifford, M. Bourbonniere, and J. Zinn. 2005. "The Employment of Nurse Practitioners and Physician Assistants in U.S. Nursing Homes." Gerontologist 45 (4): 486-95.

Intrator, O., and V. Mor. 2004. "Effect of State Medicaid Reimbursement Rates on Hospitalizations from Nursing Homes." Journal of the American Geriatrics Society 52 (3): 393-8.

Intrator, O., J. Zinn, and V. Mor. 2004. "Nursing Home Characteristics and Potentially Preventable Hospitalizations of Long-Stay Residents." Journal of the American Geriatrics Society 52 (10): 1730-6. 
Joskow, P. 1980. "The Effects of Competition and Regulation on Hospital Bed Supply and the Reservation Quality of the Hospital." Bell Journal of Economics 11 (11): 421-48.

Konetzka, R. T., E. C. Norton, P. D. Sloane, K. E. Kilpatrick, and S. C. Stearns. 2006. "Medicare Prospective Payment and Quality of Care for Long-stay Nursing Facility Residents." Medical Care 44 (3): 270-6.

Mor, V., O. Intrator, B. E. Fries, C. Phillips, J. Teno, J. Hiris, C. Hawes, and J. Morris. 1997. "Changes in Hospitalization Associated with Introducing the Resident Assessment Instrument." Journal of the American Geriatrics Society 45 (8): 1002-10.

Morris, J. N., B. E. Fries, D. R. Mehr, C. Hawes, C. Phillips, V. Mor, and L. A. Lipsitz. 1994. "MDS Cognitive Performance Scale." Journals of Gerontology 49 (4): M17482.

Morris, J. N., C. Hawes, B. E. Fries, C. D. Phillips, V. Mor, S. Katz, K. Murphy, M. L. Drugovich, and A. S. Friedlob. 1990. "Designing the National Resident Assessment Instrument for Nursing Homes." Gerontologist 30 (3): 293-307.

Morris, J. N., S. Nonemaker, K. Murphy, C. Hawes, B. E. Fries, V. Mor, and C. Phillips. 1997. "A Commitment to Change: Revision of HCFA's RAI." Journal of the American Geriatrics Society 45 (8): 1011-6.

Murtaugh, C. M., and M. P. Freiman. 1995. "Nursing Home Residents at Risk of Hospitalization and the Characteristics of Their Hospital Stays." Gerontologist 35: 35-43.

Nohlgren, S. 2004. "Patients May Lose Cherished Bed: A Bush Medicaid Cut Could Leave Nursing Home Patients Who Have to Be Hospitalized." St. Petersburg, Times, March 1, 2004.

Nyman, J. A. 1985. "Prospective and 'Cost-Plus' Medicaid Reimbursement, Excess Medicaid Demand, and the Quality of Nursing Home Care.” Journal of Health Economics 4 (3): 237-59.

Ohio Legislature. $126^{\text {th }}$ General Assembly, Amended Substitute House Bill Number 66, Sec. 5111.244. [accessed November 3, 2006]. Available at http://www.legislature. state.oh.us/BillText126/126_HB_66_EN1_N.html

Ouslander, J. G., A. D. Weinberg, and V. Phillips. 2000. "Inappropriate Hospitalization of Nursing Facility Residents: A Symptom of a Sick System of Care for Frail Older People." Journal of the American Geriatrics Society 48 (2): 230-1.

Parchman, M. L., and S. D. Culler. 1999. "Preventable Hospitalizations in Primary Care Shortage Areas." Archives of Family Medicine 8 (6): 487-91.

Porell, F. W., and M. Carter. 2005. "Discretionary Hospitalization of Nursing Home Residents with and without Alzheimer's Disease: A Multilevel Analysis.” Journal of Aging Health 17 (2): 207-38.

Reuben, D. B., J. F. Schnelle, J. L. Buchanan, R. S. Kington, G. L. Zellman, D. O. Farley, S. H. Hirsch, and J. G. Ouslander. 1999. "Primary Care of Long-Stay Nursing Home Residents: Approaches of Three Health Maintenance Organizations." Journal of the American Geriatrics Society 47 (2): 131-8.

Saliba, D., R. Kington, J. Buchanan, R. Bell, M. Wang, M. Lee, M. Herbst, D. Lee, D. Sur, and L. Rubenstein. 2000. "Appropriateness of the Decision to Transfer 
Nursing Facility Residents to the Hospital." Journal of the American Geriatrics Society 48 (2): 154-63.

Snijders, T. A. B., and R. J. Bosker. 1999. Multilevel Analysis: An Introduction to Basic and Advanced Multilevel Modeling. London: Sage.

Stambler, H. V. 1988. "The Area Resource File-A Brief Look.” Public Health Report 103 (2): 184-8.

Troyer, J. L. 2004. "Examining Differences in Death Rates for Medicaid and NonMedicaid Nursing Home Residents." Medical Care 42 (10): 985-91.

Weech-Maldonado, R., G. Neff, and V. Mor. 2003. "The Relationship between Quality of Care and Financial Performance in Nursing Homes." Journal of Health Care Finance 29 (3): 48-60.

Wiener, J. M., and D. G. Stevenson. 1998. Repeal of the 'Boren Amendment': Implications for Quality of Care in Nursing Homes, New Federalism: Issues and Options for States. Series A, No. A-20. Washington, DC: The Urban Institute.

Zhang, X., and D. C. Grabowski. 2004. "Nursing Home Staffing and Quality under the Nursing Home Reform Act." Gerontologist 44 (1): 13-23.

Zinn, J. S. 1994. "Market Competition and the Quality of Nursing Home Care." Journal of Health Politics Policy and Law 19 (3): 555-82.

Zinn, J. S., V. Mor, O. Intrator, Z. Feng, J. Angelelli, and J. A. Davis. 2003. “The Impact of the Prospective Payment System for Skilled Nursing Facilities on Therapy Service Provision: A Transaction Cost Approach." Health Services Research 38 (6 Pt 1): 1467-85.

Zwanziger, J., D. B. Mukamel, and I. Indridason. 2002. "Use of Resident-Origin Data to Define Nursing Home Market Boundaries." Inquiry 39 (1): 56-66. 